\title{
Pengembangan Virtual Laboratory Entrepreneurship sebagai sistem monitoring usaha bagi mahasiswa
}

\author{
M. Zainal Arifin1, Syaad Patmanthara², Daniar Wahyu Akbar Oktaviandi³ \\ 1. Universitas Negeri Malang, Indonesia | arifin.mzainal@gmail.com \\ 2. Universitas Negeri Malang, Indonesia | syaad.ft@um.ac.id \\ 3. Universitas Negeri Malang, Indonesia | daniar.wao@gmail.com
}

\begin{abstract}
Abstrak
Tujuan dari pengembangan virtual laboratory sebagai sistem monitoring usaha mahasiswa adalah membangun sistem yang dapat membantu Dosen untuk memantau (monitoring) progress usaha yang sedang dijalankan oleh mahasiswa, kemudian sistem yang mampu mengukur progress dari usaha mahasiswa. Model pengembangan ini dilakukan melalui 5 tahapan yaitu : (1) Requirement analysis and definitions; (2) System and software design; (3) Implementation and unit testing; (4) Integration and system testing; (5) Operation and maintenance. Metode pengujian yang digunakan adalah blackbox, yakni untuk menguji fungsionalitas dan usabilitas sistem yang dikembangkan. Berdasarkan pengujian fungsionalitas dan usabilitas oleh ahli sistem, dosen, dan mahasiswa, mendapatkan hasil yang baik untuk aspek fungsionalitas dan presentase $85.86 \%$ untuk aspek usabilitas, sehingga dapat disimpulkan bahwa sistem ini telah layak dan dapat dioperasikan. Diharapkan dengan pengembangan sistem Virtual Laboratory Entrepreneurship dapat bermanfaat bagi dosen dan mahasiswa sebagai sarana yang dapat membantu proses pengembangan usaha mahasiswa.
\end{abstract}

Kata Kunci

Virtual Laboratory, Entrepreneurship, Monitoring 


\section{TEKNO Jumal Teknologi Eektro dan Kejuruan}

http://journal2.um.ac.id/index.php/tekno | ISSN 1693-8739

\section{Pendahuluan}

Kewirausahaan merupakan proses dinamik untuk menciptakan tambahan kemakmuran. Tambahan kemakmuran ini diciptakan oleh individu wirausaha yang menanggung resiko, menghabiskan waktu, dan menyediakan berbagai produk barang dan jasa (Buchari, 2017). Kewirausahaan merupakan kemampuan untuk berwirausaha dengan menciptakan sesuatu yang baru dan berbeda (Nann, et al, 2010). Dalam kata lain, kewirausahaan dalam hal ini merupakan suatu kreativitas dan inovasi yang dimiliki untuk menghasilkan nilai tambah bagi dirinya dan bermanfaat bagi orang lain.

Konsep kewirausahaan saat ini diadaptasi oleh kurikulum pendidikan tinggi menjadi sebuah matakuliah (Wiratno, 2012). Matakuliah Kewirausahaan menjadi salah satu matakuliah pilihan bagi mahasiswa S1 Pendidikan Teknik Informatika Universitas Negeri Malang. Matakuliah ini memiliki fokus cara menjalankan usaha serta bagaimana mengembangkannya. Salah satu hasil yang diharapkan pada matakuliah ini agar mahasiswa dapat menerapkan perilaku kerja yang inovatif sesuai dengan bidangnya.

Pada proses pelaksanaan matakuliah kewirausahaan, mahasiswa secara berkelompok mendapatkan tugas untuk mulai menjalankan usaha (Subijanto, 2012). Kemudian materi yang didapatkan selama perkuliahan tidak lain bertujuan untuk pengembangan usaha dengan tahapan - tahapan yang benar. Untuk mengetahui progress dari usaha, harus diketahui bahwa langkah yang dilakukan untuk pengembangan usaha sudah dilakukan dan apakah langkah yang dilakukan tersebut sudah benar.

Diperlukan sebuah sistem yang dapat memantau (monitoring) usaha yang sedang dikembangkan mahasiswa. Saat ini sistem yang dapat memantau perkembangan usaha yang dikembangkan mahasiswa belum ada dan tenaga pengajar khusus untuk matakuliah kewirausahaan yang terbatas, menyebabkan mahasiswa tidak dapat mengetahui progress dari usaha yang sedang dikembangkan.

Sistem yang dikembangkan berupa virtual laboratory yang akan menjadi solusi dari keterbatasan sumber daya, untuk dapat membantu untuk memantau progress usaha mahasiswa. Virtual laboratory merupakan sistem yang dikembangkan dalam bentuk perangkat lunak (software) berbasis website yang akan dapat memudahkan proses tersebut dibandingkan jika sistem untuk memantau (monitoring) secara manual karena dapat diakses dari mana saja dan kapan saja menggunakan perangkat komputer maupun mobile yang terhubung dengan jaringan internet.

Virtual laboratory pernah dikembangkan untuk membantu proses pembelajaran, dengan hasil yaitu mampu meningkatkan penguasaan konsep mahasiswa pada materi tertentu dan dianggap dapat menjadi alternatif untuk mengatasi keterbatasan fasilitas. Selain itu, pernah dikembangkan perangkat lunak yang dapat melakukan monitor peforma dan tracking progress dari sebuah bisnis atau usaha, bernama BSC Designer. Perangkat lunak ini dikembangkan untuk mengukur tingkat Maturity suatu perusahaan secara top down approach. 


\section{TEKNO Jurnal Teknologi Elektro dan Kejuruan}

http://journal2.um.ac.id/index.php/tekno | ISSN 1693-8739

Berdasarkan hasil observasi awal tersebut, sebagian besar mahasiswa dan dosen menginginkan adanya sebuah sistem yang dapat memantau progress perkembangan usaha mahasiswa pada matakuliah Kewirausahaan.

\section{Metode}

Model pengembangan yang digunakan pada sistem virtual laboratory adalah model waterfall. Kelebihan dari model pengembangan waterfall adalah prosesnya yang urut, mulai dari analisa hingga support, setiap proses memiliki spesifikasinya sendiri, sehingga sebuah sistem dapat dikembangkan sesuai dengan apa yang dikehendaki.

Model waterfall meliputi (Sommerville, 2011) : (1) Requirement analysis and definitions; (2) System and software design; (3) Implementation and unit testing; (4) Integration and system testing; (5) Operation and maintenance.

Tahap pertama dalam model pengembangan waterfall adalah tahap analisis kebutuhan. Proses analisis kebutuhan bertujuan untuk mencari kebutuhan dari sistem yang akan dikembangkan. Dalam tahap ini telah dilakukan observasi awal kepada mahasiswa yang sedang atau telah menempuh matakuliah kewirausahaan dan wawancara dengan dosen pengampu matakuliah kewirausahaan. Observasi awal dan wawancara dilakukan untuk mengetahui permasalahan pada proses monitoring usaha mahasiswa serta mengetahui kebutuhan yang harus ada pada sistem yang akan dikembangkan. Observasi awal dilakukan menggunakan angket. Dari hasil observasi awal diidentifikasi bahwa permasalahan adalah belum adanya sistem untuk monitoring usaha yang sedang dikembangkan oleh mahasiswa, sehingga mahasiswa dan dosen tidak dapat mengetahui progress dari usaha yang sedang dikembangkan, sehingga dibutuhkan sistem yang dapat menampung data usaha yang sedang dikembangkan oleh mahasiswa, untuk kemudian dilakukan proses perhitungan guna menentukan progress dari usaha yang dijalankan dan proses monitoring oleh dosen.

Data yang dibutuhkan dalam desain sistem virtual laboratory ini adalah profil mahasiswa dan profil usaha diantaranya: jenis usaha, modal awal usaha, nilai produksi, pemasaran, jumlah karyawan dll. Sedangkan kebutuhan fungsional dari sistem adalah fitur sistem untuk mahasiswa, dosen dan admin yang mampu melakukan pengelolaan data mahasiswa dan dosen, pengelolaan data profil mahasiswa, data usaha, dan progress usaha oleh mahasiswa, pengelolaan data profil dosen dan monitoring usaha mahasiswa oleh dosen.

Tahap selanjutnya adalah tahap desain sistem. Desain sistem bertujuan membuat pemodelan / perancangan sistem antara lain: (a) Struktur Sistem, (b) Data Flow Diagram (DFD), (c) Entity Relationship Diagram (ERD), (d) Desain Database, dan (e) Perancangan User Interface. Pertama adalah struktur program. Struktur program utama dalam sistem ini antara lain: (1) Sistem ini terdiri dari proses pengukuran progress dan monitoring, (2) Sistem ini mempunyai 3 roles yaitu Admin, Dosen dan Mahasiswa, (3) Admin dapat melakukan pengelolaan data untuk kebutuhan sistem, (4) Dosen dapat melakukan proses monitoring dengan mengakses data mahasiswa, (5) Mahasiswa dapat menambahkan datanya pada sistem 


\section{TEKNO Jurnal Teknologi Elektro dan Kejuruan}

http://journal2.um.ac.id/index.php/tekno | ISSN 1693-8739

sebagai bahan untuk proses pengukuran progress usaha, dan (6) Tamu atau umum tidak dapat melakukan aktifitas kecuali memiliki akun. Kemudian perancangan Data Flow Diagram (DFD), yang menggambarkan pemodelan proses yang digunakan pada sistem Virtual Laboratory Entrepreneurship. DFD sekaligus merepresentasikan seluruh elemen sistem sebagai lingkaran tunggal dengan data keluaran yang ditunjukkan oleh arah panah masuk dan keluar secara berurutan.

Perancangan diagram hubungan entitas atau Entity Relationship Diagram (ERD) yang digunakan pada Virtual Laboratory Entrepreneurship menggambarkan hubungan antar entitas dalam sistem. ERD akan menentukan desain database yang digunakan dalam sistem ini. Pada database sistem terdapat total 21 tabel terdiri dari 14 tabel utama dan 7 tabel pendukung. Tahap akhir dalam desain sistem adalah perancangan user interface yang merupakan rancangan antarmuka sistem yang akan mengakomodir interaksi antara sistem dan pengguna dalam aspek fungsionalitas dan usabilitas.

Tahap implementasi sistem merupakan tahap pembuatan sistem informasi berdasarkan desain yang telah dibuat pada tahap perancangan sistem dan perangkat lunak menggunakan aplikasi pendukung yaitu Sublime Text, Framework Codeigniter, Framework CSS, PHP, Javascript dan lainnya (Ferreira, et al , 2010). Selanjutnya adalah tahap integrasi dan pengujian sistem. Pengujian sistem dimaksudkan untuk mengumpulkan data yang dapat digunakan sebagai dasar untuk menetapkan tingkat keefektifan, dan/atau daya tarik dari produk yang dihasilkan. Dalam tahap integrasi dan sistem testing dilakukan dengan pengujian menggunakan uji validasi. Pengujian ini mempunyai tujuan untuk memastikan bahwa produk sistem informasi yang dihasilkan sudah sesuai dengan analisis kebutuhan yang telah dibuat sebelumya dan layak untuk digunakan. Pengujian yang dilakukan pada Sistem Informasi Inventarisasi menggunakan metode pengujian black-box yang berfokus pada persyaratan fungsional perangkat lunak. Tahap terakhir adalah operasional dan perawatan. Pada tahap ini sistem dirancang agar dapat dioperasikan pada kegiatan perkuliahan yaitu matakuliah kewirausahaan di Jurusan Elektro Universitas Negeri Malang. Sedangkan perawatan sistem dirancang dengan dilakukannya perbaikan apabila ditemukan kesalahan pada sistem setelah dilakukan pengujian.

\section{Hasil}

Virtual Laboratoty Entrepreneurship dapat mengukur progress usaha mahasiswa dan dapat melakukan proses monitoring terhadap data mahasiswa. Kedua fungsi utama tersebut terbagi pada 2 role yaitu role mahasiswa dan role dosen. Role mahasiswa dapat mengukur progress usaha mahasiswa pada dashboard mahasiswa, seperti pada gambar 1. Sedangkan role dosen dapat melakukan proses monitoring progress usaha mahasiswa pada dashboard dosen, seperti pada Gambar 2. 


\section{TEKNurnal Teknologi Elektro dan Kejuruan}

http://journal2.um.ac.id/index.php/tekno | ISSN 1693-8739

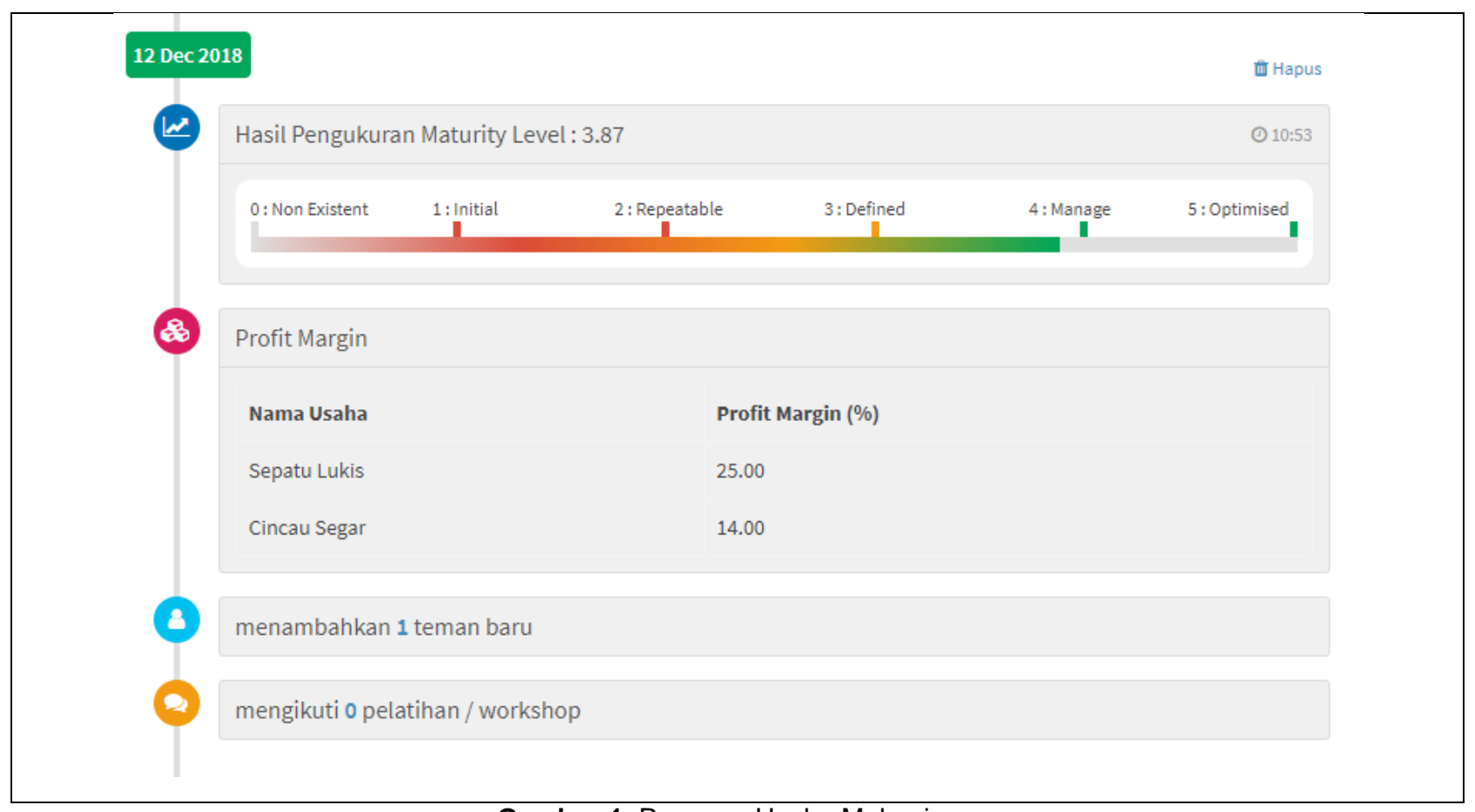

Gambar 1. Progress Usaha Mahasiswa

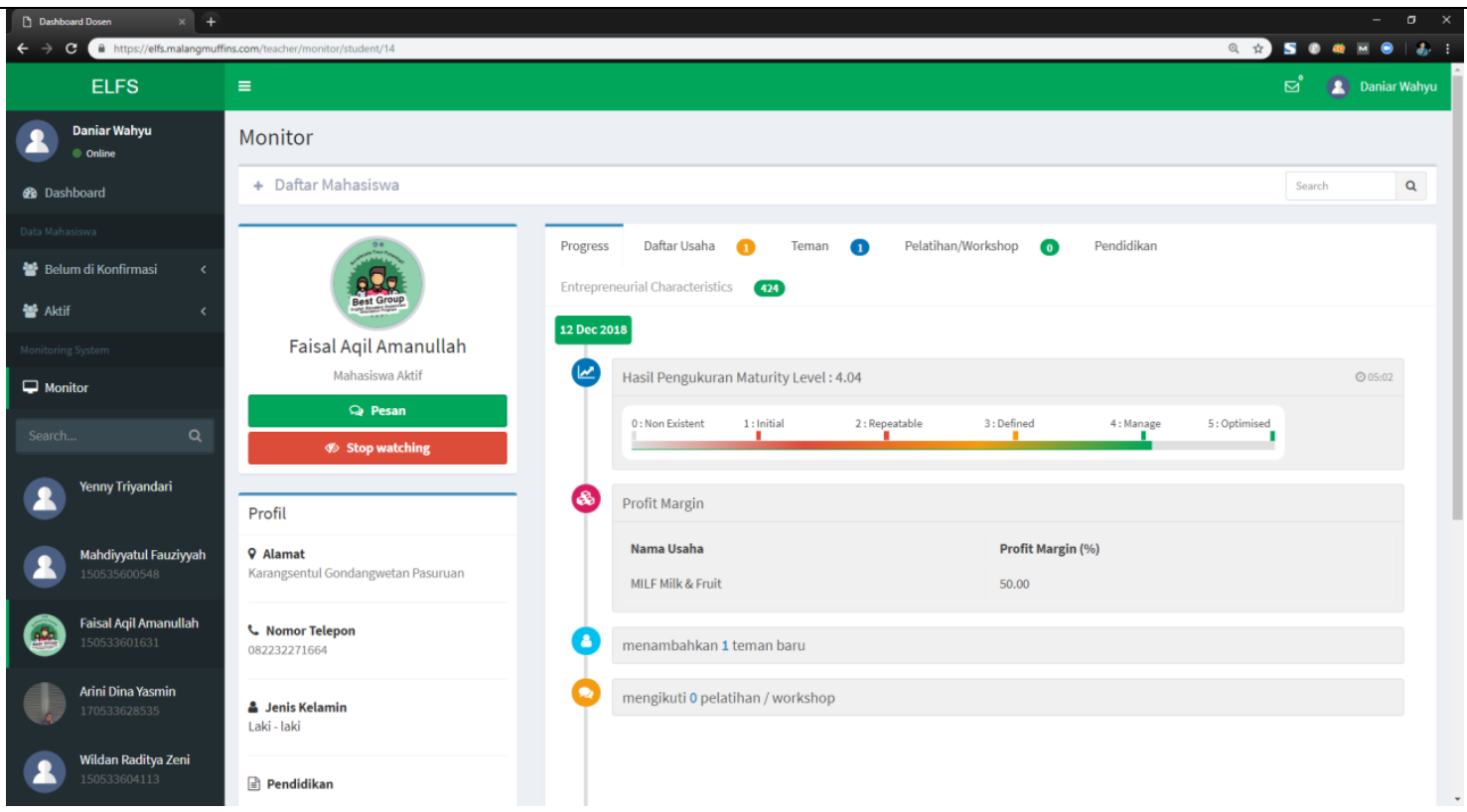

Gambar 2. Monitoring Progress Usaha Mahasiswa oleh Dosen

TEKNO Vol. 29 Issue 1, p68-74 | Jurusan Teknik Elektro, Universitas Negeri Malang, Indonesia | Maret 2019 M.Z. Arifin, S. Patmanthara, D.W.A. Oktaviandi | Pengembangan Virtual Laboratory Entrepreneurship ... 


\section{TEKNO Jurnal Teknologi Elektro dan Kejuruan}

http://journal2.um.ac.id/index.php/tekno | ISSN 1693-8739

Hasil uji coba fungsionalitas oleh ahli sistem mendapatkan nilai 1 yang berarti sistem memiliki fungsionalitas yang baik dan uji coba usabilitas oleh dosen dan mahasiswa mendapatkan persentase sebesar $85.86 \%$.

Selama proses pengujian, oleh ahli sistem, dosen, dan mahasiswa memberikan saran. Saran tersebut menjadi bahan rujukan untuk melakukan revisi produk. Saran yang diberikan oleh ahli sistem, dosen, dan mahasiswa terdapat pada Tabel 1.

Tabel 1 Saran dalam pengujian

\begin{tabular}{ll}
\hline Subjek Uji & Saran \\
\hline Ahli Sistem Informasi & Perlu memperbaiki warna untuk membedakan nilai dari hasil tes mahasiswa \\
Dosen & Perbaikan input tanggal \\
Mahasiswa & Perlu adanya petunjuk penggunaan \\
\hline
\end{tabular}

Berdasarkan analisis dari pengujian fungsionalitas oleh ahli sistem, hasil menunjukkan angka 1 yang berarti sistem memiliki fungsionalitas yang baik. Sedangkan analisis dari pengujian usabilitas oleh dosen pengampu matakuliah kewirausahaan atau sejenis dan mahasiswa, di dapatkan presentase hasil sebesar $85.86 \%$ yang menunjukkan sistem telah memenuhi standar pada aspek usabilitas.

\section{Kesimpulan}

Berdasarkan hasil pengembangan dan pembahasan yang telah dilakukan, maka didapatkan kesimpulan yaitu (1) Sistem yang dikembangkan telah layak digunakan sebagai sistem monitoring usaha bagi mahasiswa, (2) Hasil dari pengujian sistem menunjukkan nilai yang baik dalam aspek fungsionalitas dan usabilitas.

Saran yang diberikan kepada pengguna sistem Virtual Laboratory Entrepreneurship sebagai sistem Monitoring bagi mahasiswa untuk mengoptimalkan pemanfaatan produk, disarankan pengguna memperhatikan hal berikut:

a. Sistem dapat digunakan oleh semua dosen dan mahasiswa maupun umum dengan mengakses Virtual Laboratory Entrepreneurship.

b. Dosen dapat melakukan monitoring terhadap progress usaha mahasiswa melalui halaman dashboard dosen.

c. Mahasiswa dapat mengukur progress usaha melalui halaman dashboard mahasiswa.

Penggunaan produk untuk skala yang lebih luas ada beberapa hal yang perlu diperhatikan, yaitu Virtual Laboratory Entrepreneurship memerlukan sosialisasi pada mahasiswa serta dosen maupun umum agar produk dapat digunakan dengan baik. Kemudian produk dipublikasikan pada sub domain situs Jurusan Teknik Elektro Universitas Negeri Malang agar mudah diakses oleh dosen dan mahasiswa. Untuk mendapatkan performa yang maksimal, disarankan 


\section{TEKNO Junal Teknologi Elekrro dan Kejuruan}

http://journal2.um.ac.id/index.php/tekno | ISSN 1693-8739

menggunakan server yang memiliki tingkat stabilitas tinggi dan aman agar sistem ini dapat berjalan dengan maksimal.

Berdasarkan hasil analisis sistem, dikemukakan saran untuk pengembangan produk selanjutnya yakni dapat ditambahkan jenis data yang akan diisi oleh mahasiswa, kemudian menambah faktor - faktor dalam hal kewirausahaan yang dapat digunakan sebagai tambahan alat pengukuran progress usaha.

\section{Daftar Rujukan}

Alma, Buchari, Prof. Dr. H. 2017. Kewirausahaan. Bandung : Alfabeta.

Amsler, G. M. et al. 2009. Performance monitoring: guidance for the modern workplace. Supervision, 70, 12-19.

Ferreira. et al. 2010. Collaborative learning based on a micro-webserver remote test controller. Bridgeport: University of South Australia.

Nann. Et al. 2010. Comparing the structure of virtual entrepreneur networks with business effectiveness. Procedia - Social and Behavional Sciences 2.

Sommerville, lan. 2011. Software Engineering. 9th Edition. America : Pearson. Education ,Inc. Subijanto. 2012. Analisis Kebijakan Pendidikan Kewirausahaan di Sekolah Menengah Kejuruan. Jurnal Pendidikan dan Kebudayaan, Vol 18, No. 2 Edisi Juni 2012, Balitbang, Kemdikbud.

Wiratno, Siswo. 2012. Pelaksanaan Pendidikan Kewirausahaan di Pendidikan Tinggi. Jurnal Pendidikan dan Kebudayaan Badan Penelitian dan Pengembangan Kementrian Pendidika dan Kebudayaan, (Online), (http://jurnaldikbud.kemdikbud.go.id/index.php/ipnk/article/view/ 101/98), diakses 26 Maret 2018.. 